\title{
Study on the influence of supertall building load on adjacent tunnel subsidence
}

\author{
Yan Xu${ }^{1,2,3}$, Xuexin Yan ${ }^{1,2,3}$, and Tianliang Yang ${ }^{1,2,3}$ \\ ${ }^{1}$ Key Laboratory of Land Subsidence Monitoring and Prevention, Ministry of Nature and Resource of China, \\ Shanghai, 200072, China \\ ${ }^{2}$ Shanghai Institute of Geological Survey, Shanghai, 200072, China \\ ${ }^{3}$ Shanghai Engineering Research Center of Land Subsidence, Shanghai, 200072, China
}

Correspondence: Yan Xu (xuyan@sigs.com.cn)

Published: 22 April 2020

\begin{abstract}
With the rapid growth of economy in coastal megacities, the construction of supertall buildings with deep pile foundations adjacent to tunnels in soft soil is inevitable. The additional subsidence of tunnel and long-term subsidence of soft soil was appeared caused by the supertall building load transferred through pile foundation. In this paper, a typical case in Shanghai where deep piles of supertall building group adjacent to a metro tunnel was selected, and the long-term monitoring data of tunnel deformation was collected and analysed. The layered subsidence of surrounding soft soil was analysed by using the monitoring data of extensometers in a land subsidence monitoring station near the study area. The results of data analysis showed that the construction of supertall building had a significant impact on the adjacent tunnel subsidence. Moreover, with the increase of the load transferred from building structure to pile foundation, the adjacent tunnel appeared sustained uneven subsidence. And the subsidence of tunnel in the study area mainly depended on the deformation of underlying soil.
\end{abstract}

\section{Introduction}

With the rapid growth of economy in coastal megacities (e.g. Shanghai and Tokyo), the construction of supertall buildings with deep piles adjacent to metro tunnels in the soft soil is inevitable. British engineers were aware of the interaction between new pile and an existing tunnel as early as the 1950s (Measor and New, 1951). Underground subway operators have developed restrictive guidelines for the construction and loading of piles in the vicinity of tunnels based on this experience (Schroeder et al., 2004). Mohammad et al. (2013) presented a neural network combined with a finite element method to analyse the interaction between the building and adjacent metro tunnel. The friction resistance generated by supertall building pile will cause the change of foundation stress field through the stress transfer of soil mass, thus additional subsidence of these tunnels and longterm subsidence of soft soil will develop as a consequence, which will impact the tunnel stability and thus the Metro operation (Weng et al., 2016). The safety of megacities is threated by all these unpredictable problems.

In this paper, a typical case in Shanghai where deep piles of supertall building group adjacent to a metro tunnel (see Fig. 1) and the long-term monitoring data of tunnel deformation is presented. In order to accurately analyse the influence of supertall building loads, three measured data datums of the tunnel elevation were adopted respectively: the elevation when the subsidence monitoring on metro tunnel began in 1999, the elevation when the foundation pit base of Building A was completed in 2009, and the elevation at the position near the Park where was away from the building load. These results provide an example and can be used as a test case and example for similar engineering problems faced by other coastal megacities throughout the world. 


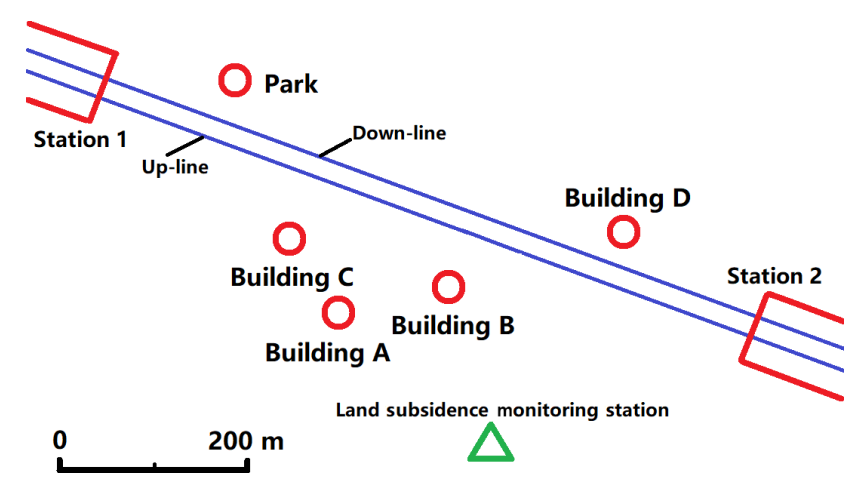

Figure 1. Plan view of the case study area.

\section{Description of project}

The construction of pile foundation for Building A started in November 2008, and the foundation pit base completed in March 2010, the main structure completed in August 2013, and the civil engineering work basically completed by the end of 2014. Building A started operation in mid-2015.

The soil composition underneath Building A within the depth of $150 \mathrm{~m}$ is mainly composed of saturated clay, silt and sand. The soil layers and test pile profile are shown in Fig. 2. The foundation pit of the main building was excavated at a depth of $31 \mathrm{~m}$. The top of the engineering pile is located in the sandy and silty soil layer, while the pile end in the silty sand layer, and the effective pile length was all located in the sandy soil layer. The water level is generally $1.0-1.7 \mathrm{~m}$ below the ground surface, while $12.3-14.2 \mathrm{~m}$ for the water head of silty confined aquifer.

The study area was selected around the metro tunnels (upline and down-line) adjacent to Buildings A-C (see Fig. 1 for details). The construction of Building $\mathrm{C}$ was started in May 1994 and structure completed in August 1997, while the construction of Building B began in November 2005 and structure completed in September 2007. The heights of Building A-C are more than $400 \mathrm{~m}$ above the ground surface. The large-diameter $(1000 \mathrm{~mm})$ and ultra-long $(88 \mathrm{~m})$ cast-insitu piles were constructed as the foundation of Building A, which were different from the steel pipe piles used in Building B and C (Jiang and Chao, 2012).

\section{Analysis of tunnel subsidence}

\subsection{Subsidence analysis since 1999}

In the study area, the subsidence monitoring on the metro tunnel began in November 1999, and this levelling results was used as the baseline for subsequent levelling analysis. Figure 3 illustrates the adjacent tunnel subsidence during the construction and operation of Building A.

It can be seen from Fig. 3 that the up-line tunnel represented a gradual trend of rebound in general, and the defor-

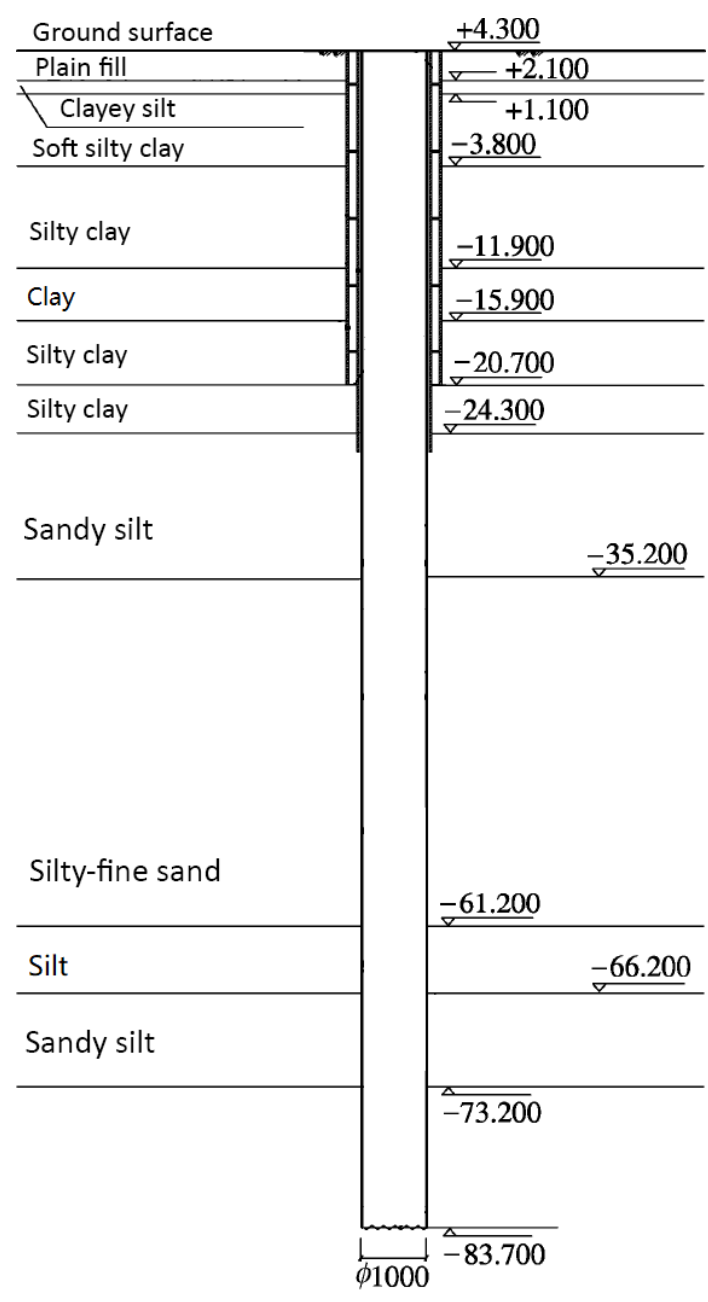

Silt

$-93.600$

Figure 2. Soil and pile profile at the study site (modified from Wang et al., 2011).

mation pattern was consistent at different positions. The cumulative subsidence of tunnel is the largest at the position of Park, and the minimum at the position of Building A, and the cumulative subsidence is relatively similar at other positions. On the whole, after the completion of civil engineering work of Building A, the overall rebound rate of the tunnel tended to decrease.

In order to clearly illustrate the differential subsidence of the station-to-station tunnel, the cumulative subsidence of the interval section was drawn with the starting point of Station 1 and the end point of Station 2 (Fig. 4). It can be seen from Fig. 4a, the levelling data of up-line tunnel, that the cumulated subsidence near Station 1 is relatively large, and there was a subsidence peak between Building $\mathrm{B}$ and $\mathrm{C}$, indicating that pile foundation group of supertall buildings had some influence on the subsidence of adjacent tunnel. Figure $4 \mathrm{~b}$ shows that the location of subsidence peak of the down-line 


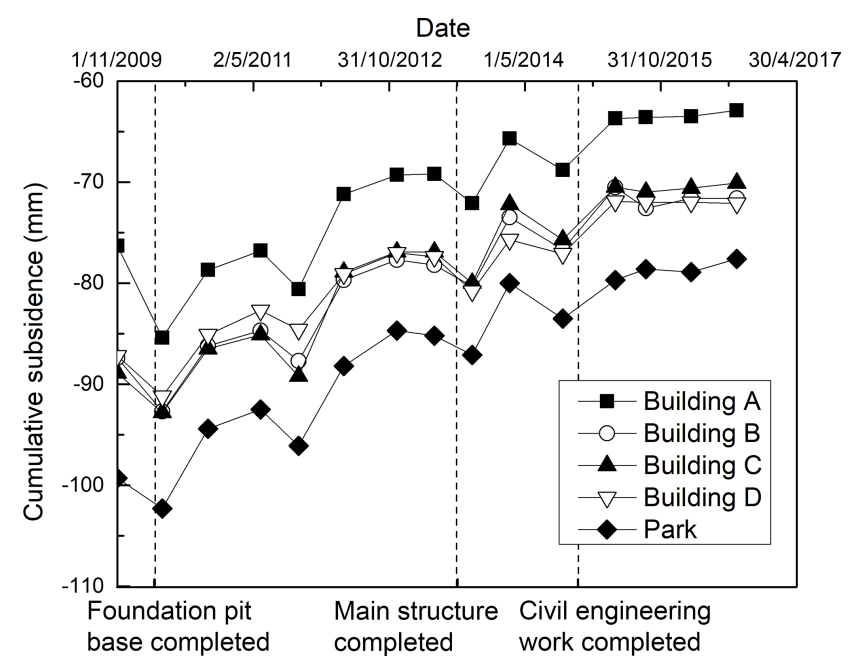

Figure 3. Tunnel subsidence at different position since 1999 during the construction and operation of Building A.

tunnel, which is relatively away from Building A, shifted eastward, and it might be related to the stress redistribution of the tunnel structure caused by the transfer of additional stress from the load of this supertall building.

\subsection{Subsidence analysis since 2009}

The structures of Building B and $\mathrm{C}$ were completed in August 1997 and September 2007 respectively. The influence of their construction and operation on adjacent tunnel cannot be ignored. In order to eliminate as far as possible, the influence of engineering activities in the study area before the load of Building A, the levelling data in November 2009, when the foundation pit base of Building A was completed, is considered as the baseline in the following analysis.

It can be seen from Fig. 5a that the cumulative subsidence (rebound) of the up-line tunnel was the largest (minimum) at the position of Building $\mathrm{A}$, while the cumulative subsidence (rebound) was the minimum (largest) at the position of Park. Figure 5a shows opposite pattern of that in Fig. 3, which suggested that the construction of Building A had a significant impact on the deformation of adjacent tunnel. Figure $5 \mathrm{~b}$ presents the deformation pattern of the down-line tunnel, and it was not typical compared with that of the up-line. The down-line tunnel is on the opposite side away from Building A, and the load of pile foundation may have been attenuated in the stress transfer process, which to some extent was benefited from the interaction between tunnel structure and surrounding soil layer.

According to the cumulative subsidence of the station-tostation tunnel in Fig. 6, the subsidence peak near Building A was obviously appeared, and was closer to Building A than that in Fig. 4. Figures 5 and 6 also show that tunnels in the study area were in a constant rebound trend due to the influence of the change of surrounding geological environment.
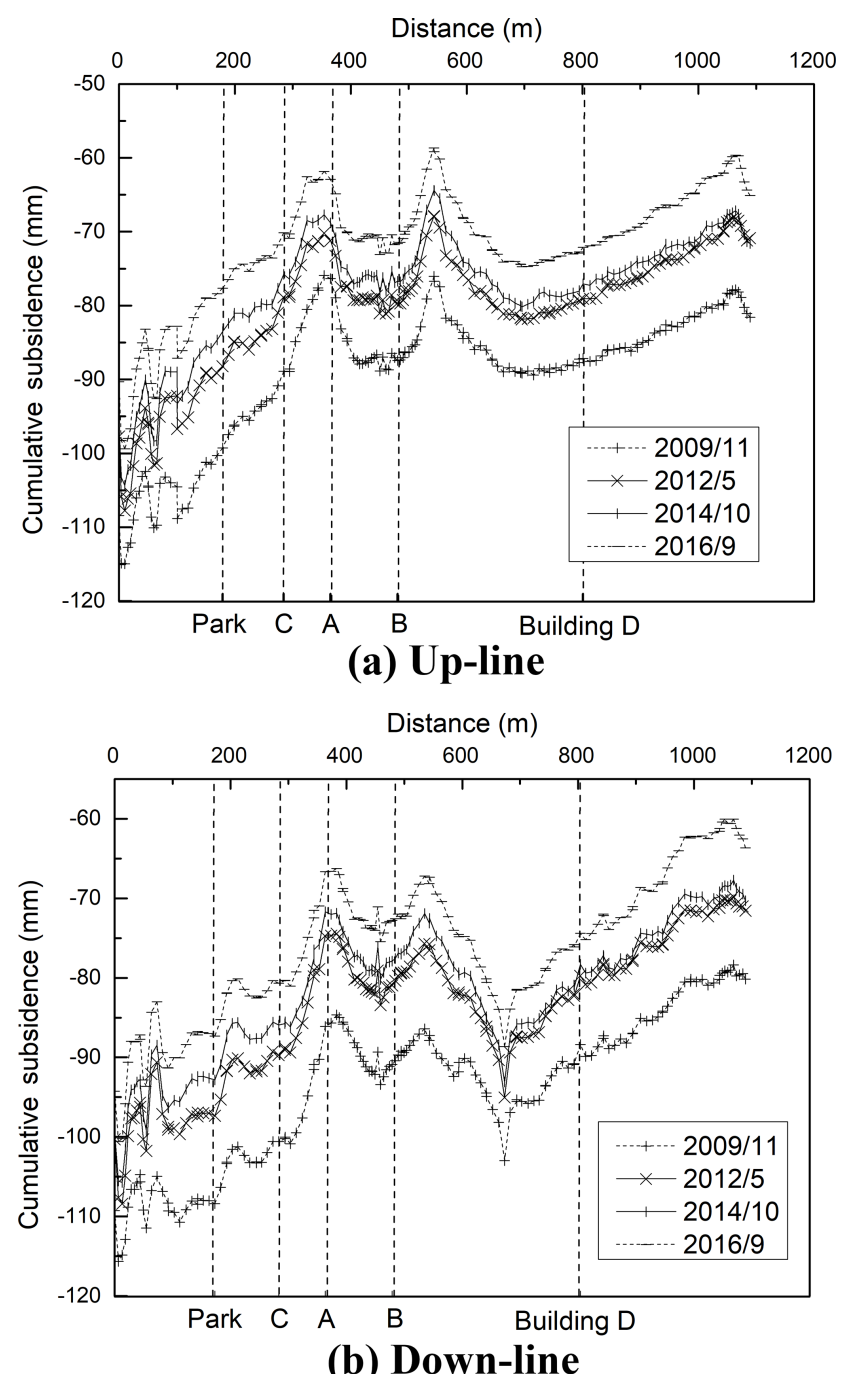

(b) Down-line

Figure 4. Subsidence of the station-to-station tunnel section since 1999.

Meanwhile, it can be seen that at the position of Park, the tunnel appeared peak of rebound.

\subsection{Uneven subsidence analysis}

The structures in each position of the station-to-station tunnel are associated with each other, so that the tunnel deformation at a certain position will cause the follow-up deformation of surrounding tunnel structures. In order to eliminate the impact of the overall rebound of the station-to-station tunnel, the point at the position of Park was adopted to be the reference, where was most significantly affected by the surrounding geological environment because it was relatively far away from the supertall buildings, to analyse the relative subsidence of tunnel in study area (Figs. 5 and 6).

Taking the tunnel elevation at the position of Park as the reference point, the relative deformation at different posi- 


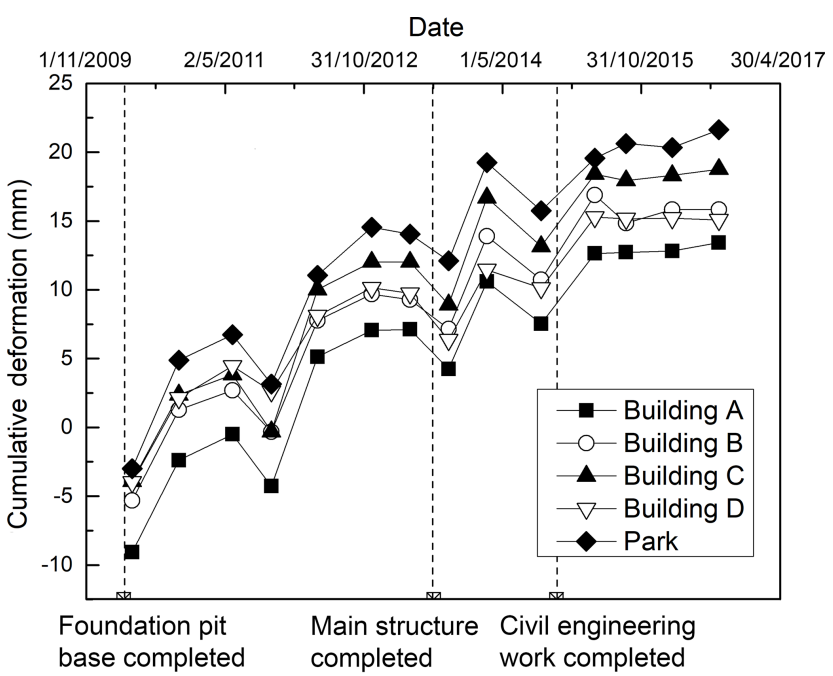

(a) Up-line

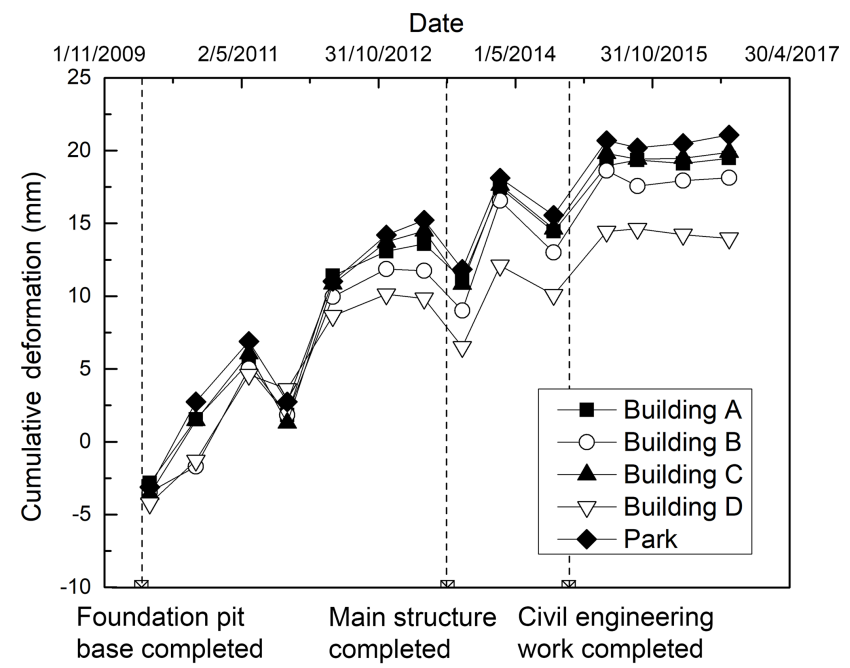

(b) Down-line

Figure 5. Tunnel deformation at different position since 2009 during the construction and operation of Building A.

tions was drawn based on the adopted initial value in November 2009 (Fig. 7). It can be seen from Fig. 7 that the whole up-line tunnel was basically in a state of relative subsidence, and the accumulated subsidence was the largest near Building $\mathrm{A}$, the pattern of which was consistent with the analysis in Sect. 3.2. Figure 7 also shows that during the Building construction period from May 2012 to March 2014, with the increase of load transferred from the structure to the pile foundation, the tunnel structure adjacent to Building A appeared continuous relative subsidence.

The uneven subsidence peak of the tunnel at the position of Building A was showed more clearly in Fig. 8a, and the relative subsidence rate tended to decrease. The down-line subsidence curve in Fig. $8 \mathrm{~b}$ illustrates that the tunnel on the side away from the supertall buildings would also be affected

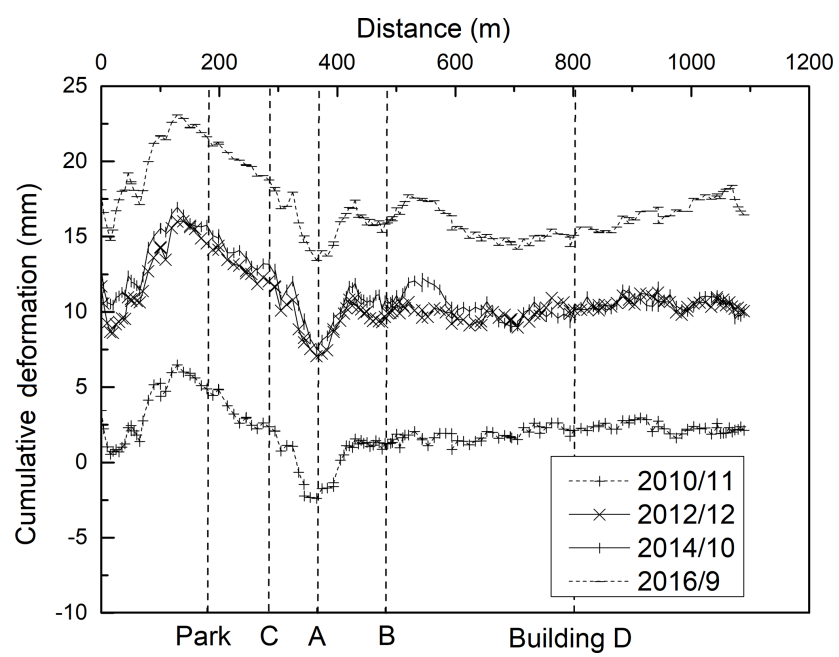

Figure 6. Deformation of the up-line station-to-station tunnel section since 2009.

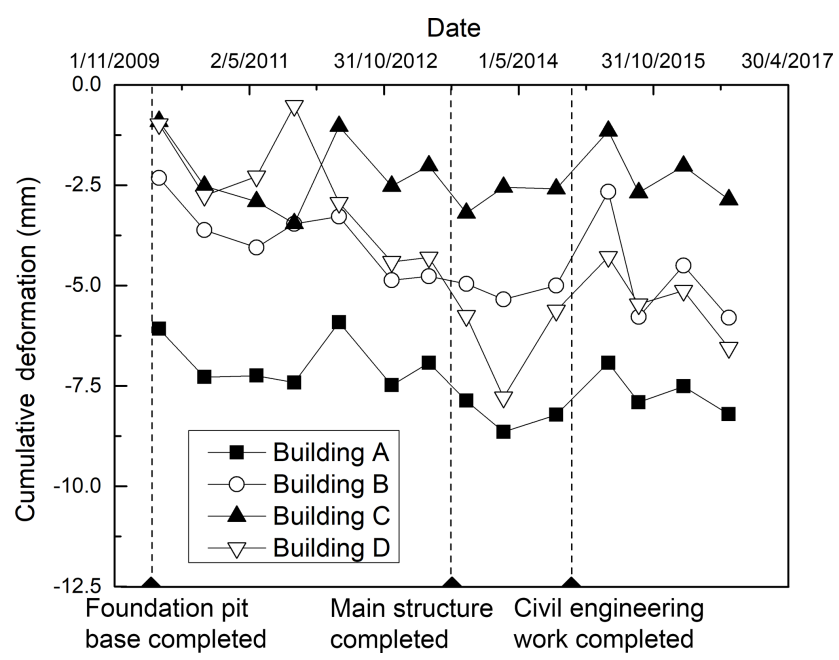

Figure 7. Relative up-line tunnel deformation at different position since 2009.

by the load transfer of pile foundation, but the effect was obviously weakened, which demands for further research.

\section{Analysis of soil layer deformation}

A land subsidence monitoring station (LSMS) is located within $300 \mathrm{~m}$ from Building A and the tunnels (see Fig. 1), in which a group of extensometers were installed. The extensometers were often used to monitor soil deformation (Yang et al., 2015). According to the monitoring data, the layered deformation of soil in this area after November 2009 is illustrated in Fig. 9.

Figure 9 shows that the main deformation of the soil in this region occurred in the shallow layer $(1.2-15.5 \mathrm{~m})$, where the tunnels in the study area were located. Figure 9 also il- 


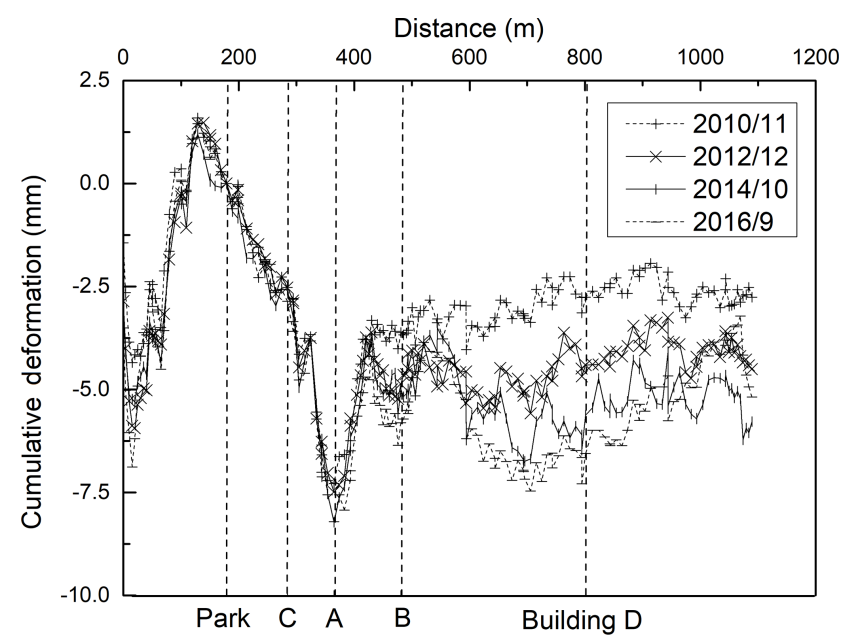

(a) Up-line

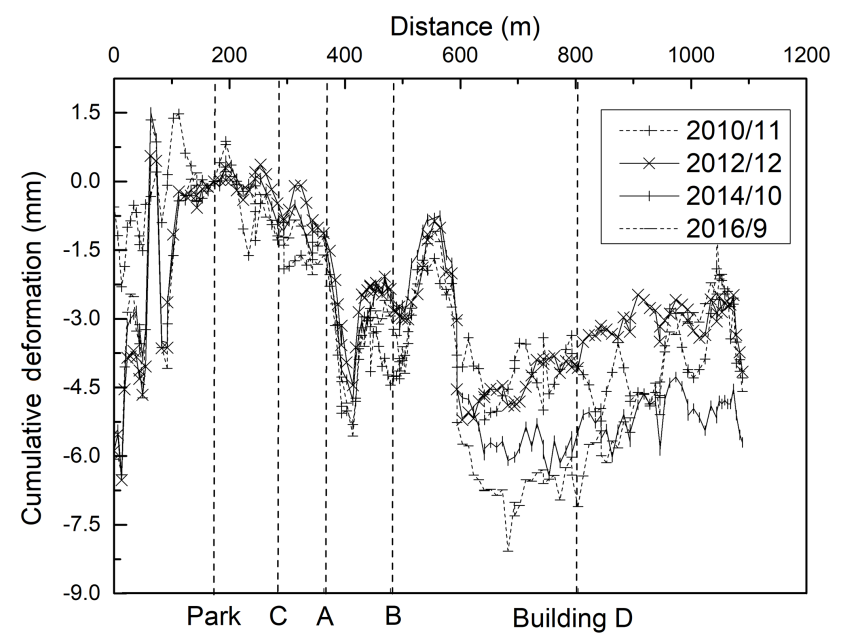

(b) Down-line

Figure 8. Relative deformation of the station-to-station tunnel section since 2009.

lustrates that, before the structure completion of Building A, the land subsidence rate was basically lower than the deformation rate of shallow soil layer. After the structure completion of Building A, the land subsidence rate gradually exceeded the deformation rate of shallow soil layer, which indicated that the load of the supertall building was gradually transferred to the deeper soil layer through pile foundation, resulting in the compression of the deeper soil layers. Comparing with Fig. 6, it can be seen that the subsidence of metro tunnel mainly depended on the deformation of soil layer beneath the tunnel structure. Therefore, to study on the impact of pile foundation load on adjacent tunnels, the stress transfer pattern and deformation of deep soil layers under supertall building load should be focused on.

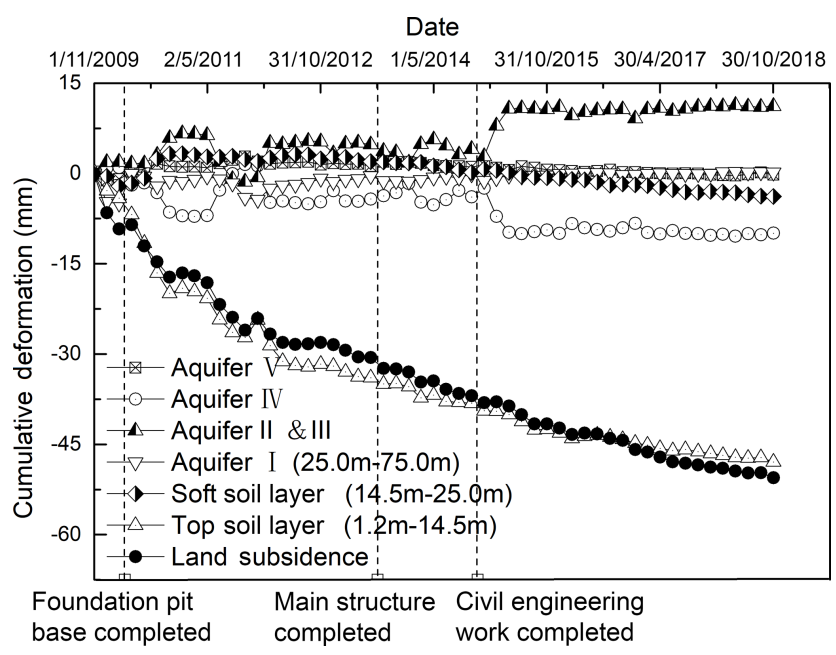

Figure 9. Layered deformation of soil in study area since 2009.

\section{Conclusions}

In this study, the field monitoring data analyses were performed to evaluate the influence of supertall building load on adjacent tunnel subsidence. Based on the results, the following conclusions can be drawn:

1. the construction of Building A had a significant impact on the adjacent tunnel subsidence;

2. with the increase of the load transferred from building structure to pile foundation, the tunnel adjacent to Building A appeared sustained uneven subsidence;

3. the subsidence of tunnel in the study area mainly depended on the deformation of underlying soil, and the stress transfer pattern was the key to evaluate the influence of high-rise building load on adjacent tunnel.

Data availability. All data generated or used during the study appear in the submitted article.

Author contributions. YX did the formal analysis and wrote the paper. XY and TY were responsible for the conceptualization and supervision of the project.

Competing interests. The authors declare that they have no conflict of interest.

Special issue statement. This article is part of the special issue "TISOLS: the Tenth International Symposium On Land Subsidence - living with subsidence". It is a result of the Tenth International Symposium on Land Subsidence, Delft, the Netherlands, 17-21 May 2021. 
Acknowledgements. This is a contribution of the IGCP-663 project "Impact, Mechanism, Monitoring of Land Subsidence in Coastal cities" of the IUGS and UNESCO.

Financial support. This research has been supported by the International Geoscience Programme (grant no. IGCP 663) and the Shanghai Science and Technology Commission (grant no. 18DZ1201100).

\section{References}

Jiang, W. H. and Chao, S.: Variable rigidity design in the pile foundation of Shanghai Tower, Build. Struct., 42, 131-134, 2012.

Measor, E. O. and New, D. H.: The design and construction of the Royal Festival Hall, South Bank, J. Inst. Civ. Eng., 36, 241-318, 1951.
Mohammad, A., Shahram, P., and Ali, K.: Assessment of optimum settlement of structure adjacent urban tunnel by using neural network methods, Tunnel. Undergr. Space Technol., 37, 1-9, 2013.

Schroeder, F. C., Potts, D. M., and Addenbrooke, T. I.: The influence of pile group loading on existing tunnels, Geotechnique, 54, 351362, 2004.

Wang, W. D., Li, Y. H., and Wu, J. B.: Field loading tests on largediameter and super-long bored piles of Shanghai Center Tower, Chin. J. Geotech. Eng., 33, 1817-1826, 2011.

Weng, X. L., Sun, T., and Feng, Y.: Influence of loading pile foundation on existing neighboring subway tunnel, J. Harb. Inst. Technol., 48, 138-142, https://doi.org/10.11918/j.issn.03676234.2016.03.023, 2016.

Yang, T. L., Yan, X. X., Wang, H. M., Huang, X. L., and Zhan, G. H.: Comprehensive experimental study on prevention of land subsidence caused by dewatering in deep foundation pit with hanging waterproof curtain, Proc. IAHS, 372, 1-5, https://doi.org/10.5194/piahs-372-1-2015, 2015. 